\title{
Characterizing urban pollution variability in Central Poland using radon-222
}

Scott D. Chambers $(1)$ Agnieszka Podstawczyńska $\mathbb{0}$

\begin{abstract}
Four years of observations of radon, meteorology and atmospheric pollution was used to demonstrate the efficacy of combined diurnal and synoptic timescale radon-based stability classification schemes in relating atmospheric mixing state to urban air quality in Zgierz, Central Poland. Nocturnal radon measurements were used to identify and remove periods of non-stationary synoptic behaviour (13-18\% of each season) and classify the remaining data into five mixing states, including persistent temperature inversion (PTI) conditions, and non-PTI conditions with nocturnal conditions ranging from well mixed to stable. Mixing state classifications were performed completely independently of site meteorological measurements. World Health Organization guideline values for daily $\mathrm{PM}_{2.5} / \mathrm{PM}_{10}$ were exceeded only under strong PTI conditions (3-15\% of non-summer months) or often under non-PTI stable nocturnal conditions (14-20\% of all months), when minimum nocturnal mean wind speeds were also recorded. In non-summer months, diurnal amplitudes of NO (CO) increased by the factors of 2-12 (3-7) from well-mixed nocturnal conditions to PTI conditions, with peak concentrations occurring in the morning/evening commuting periods. Analysis of observations within radon-derived atmospheric mixing 'class types' was carried out to substantially clarify relationships between meteorological and air quality parameters (e.g. wind speed vs. $\mathrm{PM}_{2.5}$ concentration, and atmospheric mixing depth vs. $\mathrm{PM}_{10}$ concentration).
\end{abstract}

Keywords: Aerosols • Air quality $\bullet$ Boundary layer $\bullet$ Radon $\bullet$ Stability $\bullet$ Urban

\section{S. D. Chambers}

Environmental Research, ANSTO

Locked Bag 2001, Kirrawee DC, NSW 2232, Australia

A. Podstawczyńska ${ }^{\bowtie}$

Faculty of Geographical Sciences

Department of Meteorology and Climatology

University of Lodz

Narutowicza 88 St., 90-139 Łódź, Poland

E-mail: agnieszka.podstawczynska@geo.uni.lodz.pl

Received: 1 October 2019

Accepted: 23 January 2020

\section{Introduction}

Exposure to atmospheric pollution contributes to millions of premature deaths annually $[1,2]$. Pollution concentrations vary as a complex function of controllable and uncontrollable factors [1] where controllable factors include source types, their spatial and temporal variability, urban design, etc. and uncontrollable factors include prevailing meteorology, geographic setting (topography and proximity to the coast) and pollution advection from other regions. Historically, urban pollution has scaled with population [3], so careful planning of new urban centres and pollution mitigation for existing and growing urban regions to minimize exposure risks is required. The magnitude of this problem, considered globally, necessitates reliance on air quality models. To develop or improve such models, and evaluate mitigation measures, an improved understanding of pollution variability is required.

Mitigation measures can target only controllable pollution influences. To evaluate mitigation measures and better diagnose inaccuracies pertaining to model physics, chemistry or emissions inventories, it is helpful to separate controllable and uncontrollable 
influences on pollution variability. One way to do this is 'class typing' based on the atmospheric mixing state $[4,5]$. Forming classes of similar atmospheric conditions reduces the within-group variability of meteorological controls on pollution, thereby allowing a more targeted investigation of controllable factors within each class. Comparing statistics for atmospheric class types also helps to bridge the 'scale gap' between simulation and observation of meteorological and air quality parameters.

The atmospheric mixing state (or 'stability') can change on many timescales; here we pay particular attention to diurnal, synoptic and seasonal changes. Conventional meteorological measures of atmospheric stability are typically approximate (i.e. categorical; e.g. Pasquil-Gifford schemes) or not well suited to the heterogeneous urban environment (Richardson number, Monin-Obukhov similarity theory). Consequently, this study employs a combination of two radon $\left({ }^{222} \mathrm{Rn}\right)$-based techniques [5-8] for diurnal and synoptic timescale stability classification. Radon's well-established history of application in atmospheric mixing studies [9-12] is testimony to the robustness and versatility of this tool.

This article summarizes, and builds upon, a recent two-part study $[13,14]$ discussed at the 3rd International Conference on Radon in the Environment in Krakow in May 2019. We demonstrate the efficacy of combined diurnal and synoptic timescale radon-based stability classification, and its value in improving understanding of changes in mixing state on urban pollution in all seasons, across which source types, strengths and the mixing state change significantly. Examples are also provided on the ways in which class typing based on near-surface radon measurements can improve relationships between observed meteorological parameters and various air quality measures. The summarized results constitute a valuable set of benchmarking data for future evaluation of chemical transport models operated in Central Poland.

\section{Methods}

\section{Site and observations}

This study, conducted for a period of four years (2008-2011), analyses meteorological, air quality and radon $\left({ }^{222} \mathrm{Rn}\right)$ measurements in Central Poland. Meteorological and air quality data were collected in Zgierz (N $51.8567^{\circ}, \mathrm{E} 19.4212^{\circ}$ ), $10 \mathrm{~km}$ north of Łódź. Radon was measured in Ciosny, $8 \mathrm{~km}$ north of Zgierz. Zgierz is bisected by two national motorways, and the monitoring site was $\sim 1 \mathrm{~km}$ east of the intersection of these motorways. Detailed site and equipment information is provided by Podstawczyńska and Chambers [13, 14]. Meteorological measurements included shortwave radiation (in $\mathrm{W} \cdot \mathrm{m}^{-2}$ ); temperature (in ${ }^{\circ} \mathrm{C}$ ), relative humidity (in \%), precipitation (in $\mathrm{mm} \cdot \mathrm{h}^{-1}$ ), wind speed (in $\mathrm{m} \cdot \mathrm{s}^{-1}$ ) and wind direction $\left(^{\circ}\right)$. Air quality observations included nitric oxide ( $\mathrm{NO}$; in $\mu \mathrm{g} \cdot \mathrm{m}^{-3}$ ), nitrogen dioxide $\left(\mathrm{NO}_{2}\right.$; in $\left.\mu \mathrm{g} \cdot \mathrm{m}^{-3}\right)$, carbon monoxide $(\mathrm{CO}$; in $\left.\mathrm{mg} \cdot \mathrm{m}^{-3}\right)$, sulphur dioxide $\left(\mathrm{SO}_{2}\right.$; in $\left.\mu \mathrm{g} \cdot \mathrm{m}^{-3}\right)$ and aerosols $\left(\mathrm{PM}_{10}\right.$ and $\mathrm{PM}_{2.5}$; in $\left.\mu \mathrm{g} \cdot \mathrm{m}^{-3}\right)$. All air quality instruments sampled from $4 \mathrm{~m}$ a.g.l. Atmospheric radon (predominantly ${ }^{222} \mathrm{Rn}$; see [14]) was measured at $2 \mathrm{~m}$ a.g.l., using an AlphaGUARD (PQ2000PRO) in diffusion mode in a shelter.

\section{Radon-based atmospheric stability classification}

Since ${ }^{222} \mathrm{Rn}$ is unreactive, not affected by washout and does not attach to aerosols, its primary sink is radioactive decay $\left(t_{0.5}=3.82 \mathrm{~d}\right)$. Compared with urban pollutants, it has a well-constrained and temporally consistent surface source at the urban scale and does not accumulate in the atmosphere on greater than synoptic timescales, but it is roughly conservative over a single night. This combination of physical characteristics makes radon a convenient and unambiguous tracer of vertical mixing in the boundary layer $[5,11,12]$.

For atmospheric stability analysis, radon observations must resolve the diurnal cycle (i.e. temporal resolution of $\leq 4 \mathrm{~h}$ ), for which active detectors are required. A range of direct and 'by progeny' active detectors are available $[15,16]$, with detection limits spanning several orders of magnitude. The two-filter ANSTO radon detectors [6, 17] have detection limits ranging from $0.005 \mathrm{~Bq} \cdot \mathrm{m}^{-3}$ to $0.04 \mathrm{~Bq} \cdot \mathrm{m}^{-3}$. By contrast, detectors such as the AlphaGUARD or RAD7 have detection limits of order 2-3 $\mathrm{Bq} \cdot \mathrm{m}^{-3}$. Ultimately, detector requirements are site- and application-specific.

Radon time series spanning one or more years constitute a superposition of influences at least from three timescales: (i) seasonal changes in the regional radon source function driven by soil moisture and freezing; (ii) synoptic timescale changes in air mass time-over-land resulting from the behaviour of synoptic weather systems, and (iii) dilution associated with diurnal changes in boundary layer depth. This study employs combined diurnal and synoptic radon-based stability classification techniques, separately for each season, in order to separately address these contributions.

The radon-based diurnal stability classification technique for this site has already been described by Chambers et al. [5]. Briefly, the approach involves isolating boundary layer mixing-related changes in radon concentration by estimating and removing air mass fetch effects and then assigning stability thresholds to mean values of radon accumulation within a defined nocturnal sampling window. Corresponding daytime mixing states for each 24-h period are inferred based on assumed short-term atmospheric persistence. The technique for synoptic timescale stability classification, pioneered by Kikaj et al. [8], was adapted for this site by Chambers and Podstawczyńska [14]. Briefly, this method involves separating synoptic timescale radon variability from contributions occurring at other timescales and then comparing the magnitudes of radon variability occurring at diurnal and synoptic timescales. When synoptic contributions exceed the typical magnitude 
Table 1. Average composite seasonal occurrence (in \%) of each atmospheric mixing class (only valid hourly data each season are reported)

\begin{tabular}{|c|c|c|c|c|c|}
\hline $\begin{array}{l}\text { Mixing } \\
\text { class }\end{array}$ & Comment & Winter & Spring & Summer & Autumn \\
\hline$\overline{1}$ & $\begin{array}{l}\text { Moderate to strong or gusty winds, non-stationary synoptic condi- } \\
\text { tions (fronts, etc.), rainfall common }\end{array}$ & 13 & 18 & 17 & 16 \\
\hline 2 & Moderate to strong winds, often overcast, rainfall common & 14 & 18 & 17 & 15 \\
\hline 3 & Light to moderate winds, cloudy to overcast, occasional rainfall & 13 & 18 & 16 & 15 \\
\hline 4 & Light winds, scattered cloud (mostly clear), rainfall uncommon & 14 & 18 & 17 & 16 \\
\hline 5 & $\begin{array}{l}\text { Calm to light winds, mostly clear skies, convective daytime rainfall } \\
\text { if any }\end{array}$ & 14 & 20 & 17 & 16 \\
\hline PTI & Near-calm, fog/haze common & 30 & 5 & 0 & 20 \\
\hline
\end{tabular}

of diurnal ones for more than two consecutive days, a synoptic persistent temperature inversion (PTI) event is considered to have occurred. Such events are common throughout Europe in non-summer months [8] and they can result in life-threatening high pollutant concentrations for vulnerable citizens (the elderly, the very young or asthmatics).

A summary of mixing classes employed for this site is presented in Table 1 which also includes the average occurrence frequencies per composite season of each mixing class. For subsequent analysis, class \#6 (PTI) days have been further subdivided into 'strong' and 'weak' categories based on the amplitude of diurnal radon variability observed within that class (using the median value as the selection threshold). Only the strong PTI events are discussed further. Since class \#1 days can contain a large proportion of non-stationary synoptic conditions (e.g. passing frontal weather systems), they have been excluded from further analysis.

\section{Results and discussion}

We formed diurnal composites of wind speed and near-surface temperature gradient (conventional meteorological stability indicators) within each of our radon-defined mixing classes (Fig. 1). For non-winter months, nocturnal mean wind speeds were consistently highest for class \#2 days and lowest for class \#5 days. Corresponding temperature gradients were lowest on class \#2 days and highest on class \#5 days. In winter, only the class \#5 and strong PTI days exhibited nocturnal wind speeds and temperature gradients which were clearly distinct from classes \#2 to \#4 days. Nocturnal wind speeds and temperature gradients on strong winter PTI days were clearly distinct from class \#5 days and most comparable with classes \#4 and \#5 days of other seasons. Evident from the temperature gradients (Fig. 1e,g), the number of daytime sunshine hours (effective day length) of strong PTI days in spring and autumn was lower than for days of other classes (presumably due to fog, smog or cloud), which would limit the capacity of the atmosphere to disperse pollutants that had built up through the night.

Diurnal cycles of the traffic and combustion-related gases $\mathrm{CO}, \mathrm{NO}$ and $\mathrm{NO}_{2}$ (Fig. 2) were bimodal, with peaks in the morning and evening. With the exception of NO, evening peaks were larger and broader than the morning peaks, due to the added contribution of domestic combustion to the diminishing evening vehicle emissions and the typically low nocturnal mixing heights. The lowest diurnal
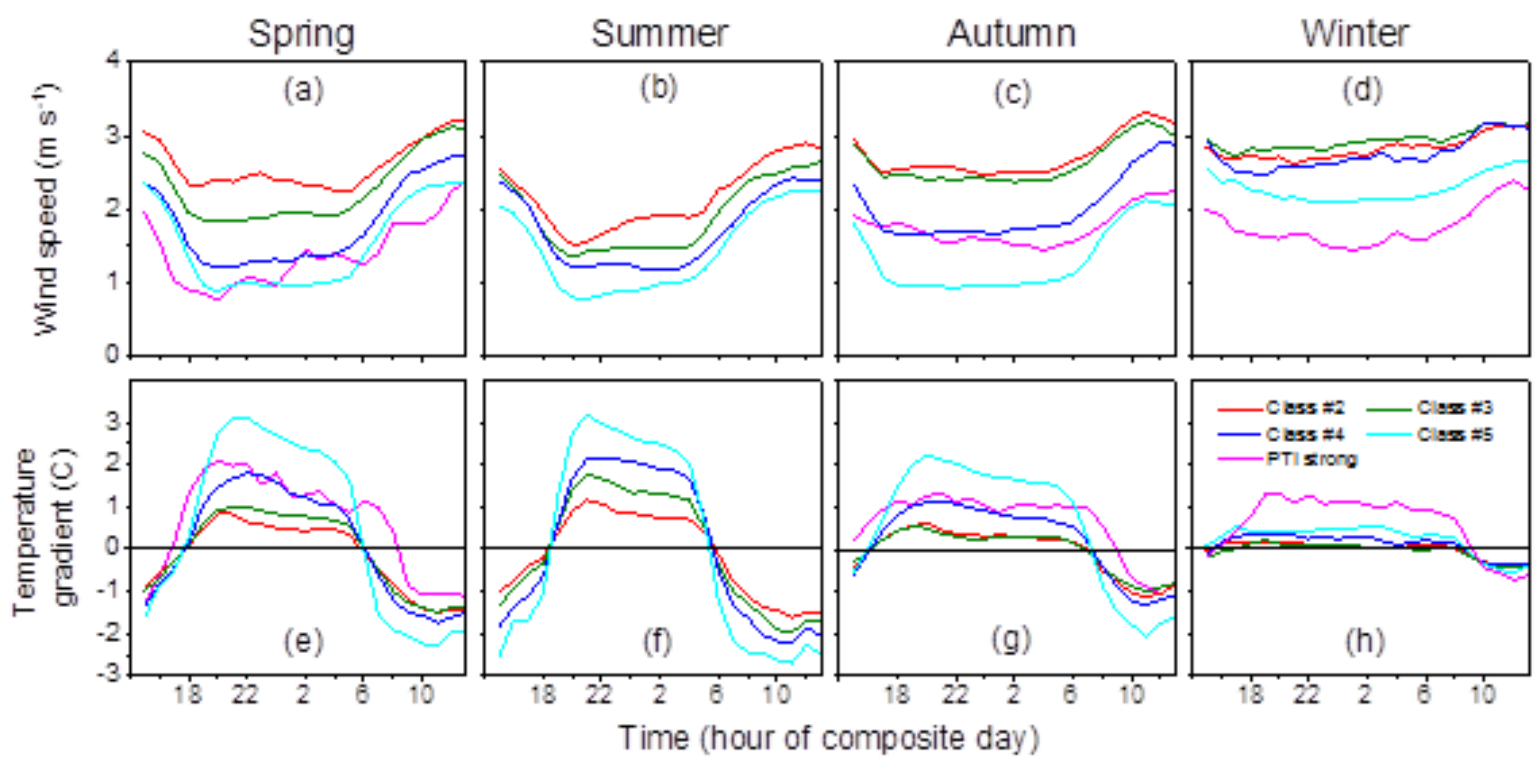

Fig. 1. Diurnal composite $(\mathrm{a}-\mathrm{d})$ wind speed and $(\mathrm{e}-\mathrm{h}) 2.0-0.2 \mathrm{~m}$ temperature gradient by radon-derived stability class and season. Note time axis shift. 

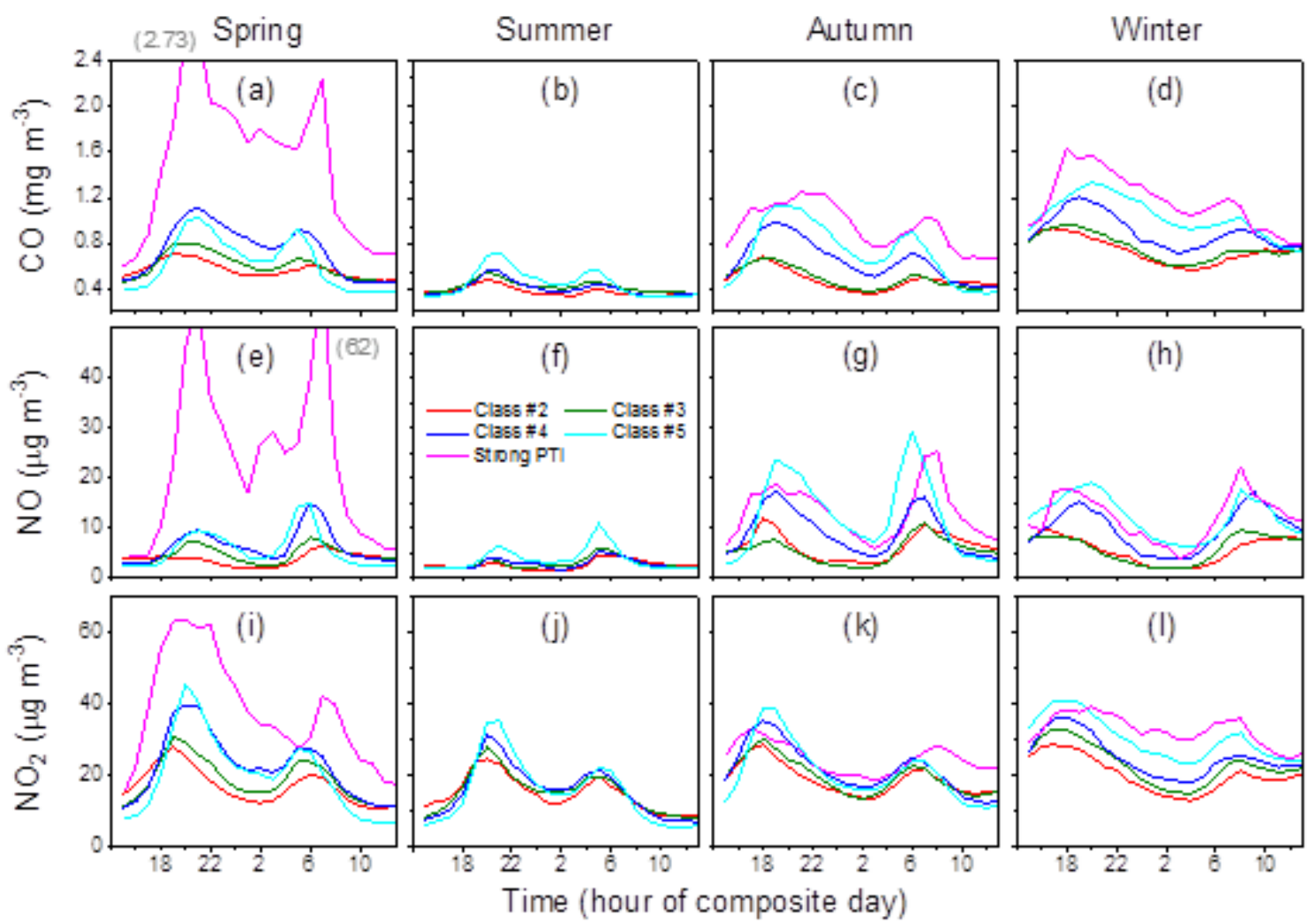

Fig. 2. Diurnal composites of $\mathrm{NO}_{2}, \mathrm{NO}$ and $\mathrm{CO}$ by season and radon-based mixing class.

cycle amplitudes of all pollutants were observed on class \#2 days, for which atmospheric mixing was strong and most uniform over the diurnal cycle, and comparatively deep at night.

In all cases, pollutant concentrations were highest under either class \#5 or strong PTI conditions. Winter snow cover, and generally higher wind speeds, prevented nocturnal mixing depths from becoming as shallow as in other seasons. Based on nocturnal radon accumulation [5], estimated nocturnal mixing depths on class \#5 (averaged across all seasons) days are $<20 \mathrm{~m}$ at the rural Ciosny, but $>40$ m over central Lodz. By comparison, estimated nocturnal mixing depths during winter strong PTI events at Ciosny are $\sim 50 \mathrm{~m}$ [14]. Class \#5 nocturnal mixing depths at Zgierz are expected to be deeper than at Ciosny (due to the simple Zgierz urban canopy architecture and low mean urban canopy height compared with the rural region), but not as deep as for Lodz. Consequently, despite continued traffic emissions and the highest domestic fuel consumption in winter, pollution concentrations did not reach the same levels experienced under spring strong PTI conditions during which nocturnal mixing depths were shallower. Another factor contributing to the high spring pollutant concentrations is that the quality of fuel burned at that time each year in Zgierz can be poor. As reported by Podstawczyńska and Chambers [13], daily minimum temperatures can be at or below zero for more than half of spring which would maintain a relatively high domestic fuel use.

Diurnal cycles of particulate matter and $\mathrm{SO}_{2}$ were also bimodal (Fig. 3) but with the evening peak dominating much more than was the case for
$\mathrm{CO}$ and $\mathrm{NO}_{x}$ (Fig. 2). Comparing the peak magnitudes for $\mathrm{PM}_{2.5}$ in summer with those in other months indicates that combustion sources (non-vehicle-related) dominate in non-summer months. A similar comparison for $\mathrm{PM}_{10}$ indicates that vehicles constitute a considerable source of $\mathrm{PM}_{10}$. Comparing peak $\mathrm{SO}_{2}$ concentrations in summer with those in spring and autumn suggests that vehicles are responsible for much of the $\mathrm{SO}_{2}$ observed in Zgierz. The comparatively low $\mathrm{SO}_{2}$ diurnal cycle in winter provides further evidence that the day/night change in winter mixing depth is not as large as for other seasons and specifically that the winter nocturnal mixing depths are substantially deeper than their non-winter counterparts [14].

On average, the World Health Organization (WHO) daily $\mathrm{PM}_{2.5}$ guideline value $\left(25 \mu \mathrm{g} \cdot \mathrm{m}^{-3}\right)$ was exceeded for strong PTI events of all seasons. The WHO $\mathrm{PM}_{2.5}$ guideline value was also reached by class \#5 days in autumn and it was exceeded under all conditions in winter. The WHO daily $\mathrm{PM}_{10}$ guideline value $\left(50 \mu \mathrm{g} \cdot \mathrm{m}^{-3}\right)$ was exceeded for strong PTI events of all seasons and also on winter class \#5 days. These observations are testimony to the ability of radon-based stability classification to relate health-related air quality information to changes in the atmospheric mixing state occasionally brought about by subtle changes in separate meteorological quantities.

Numerous studies have commented on a dependence of urban aerosol concentrations on wind speed, but specific relationships derived have varied. The dependence of $\mathrm{PM}_{2.5}$ on wind speed in Zgierz, based on all hourly data, is shown in Fig. 4a. Com- 


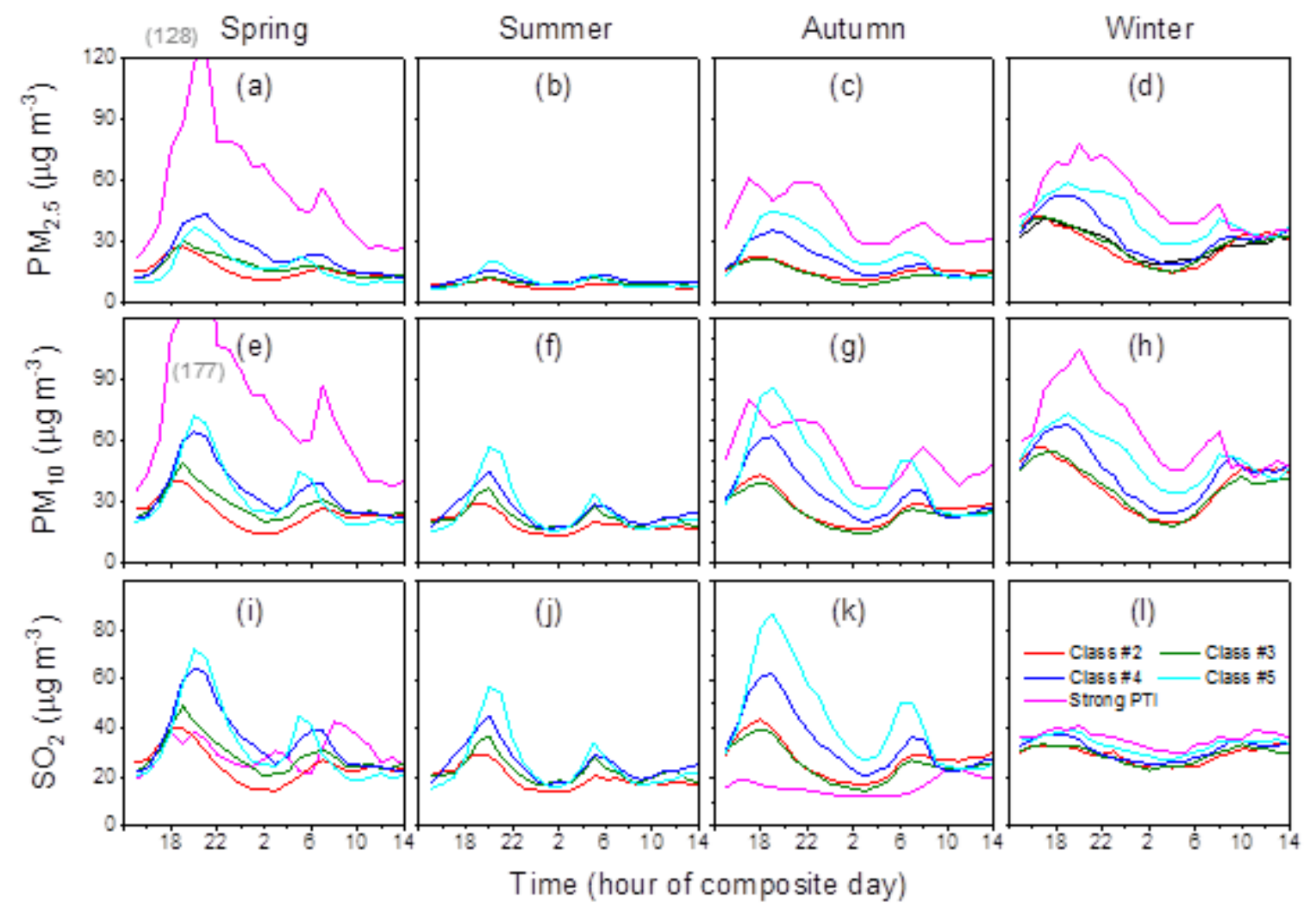

Fig. 3. Diurnal composites of $\mathrm{SO}_{2}, \mathrm{PM}_{10}$ and $\mathrm{PM}_{2.5}$ by season and radon-based mixing class.

positing this data by mixing class (Fig. 4 b) reduces the overall scatter, but it still leads to an ambiguous result (as indicated by the dashed lines). Over a full diurnal cycle, however, it is not only the changes in
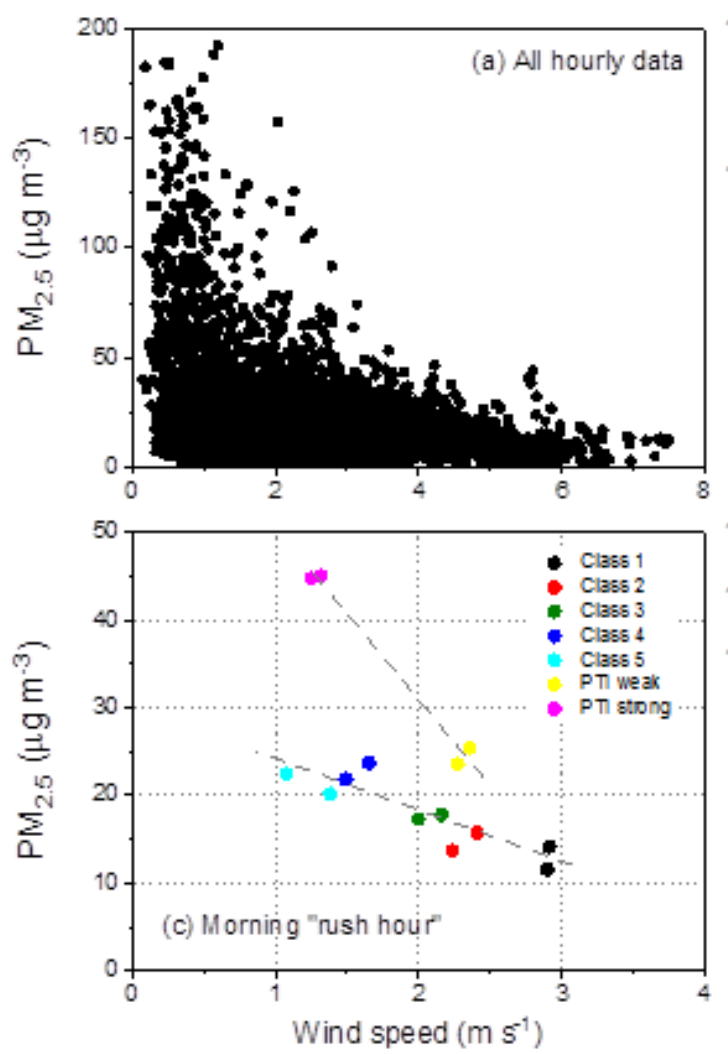

wind speed but also the changes in source strength and dilution (mixing depth). Figure $4 \mathrm{c}, \mathrm{d}$ focus only on the restricted morning and evening 'rush hour' periods, during which times source strength and
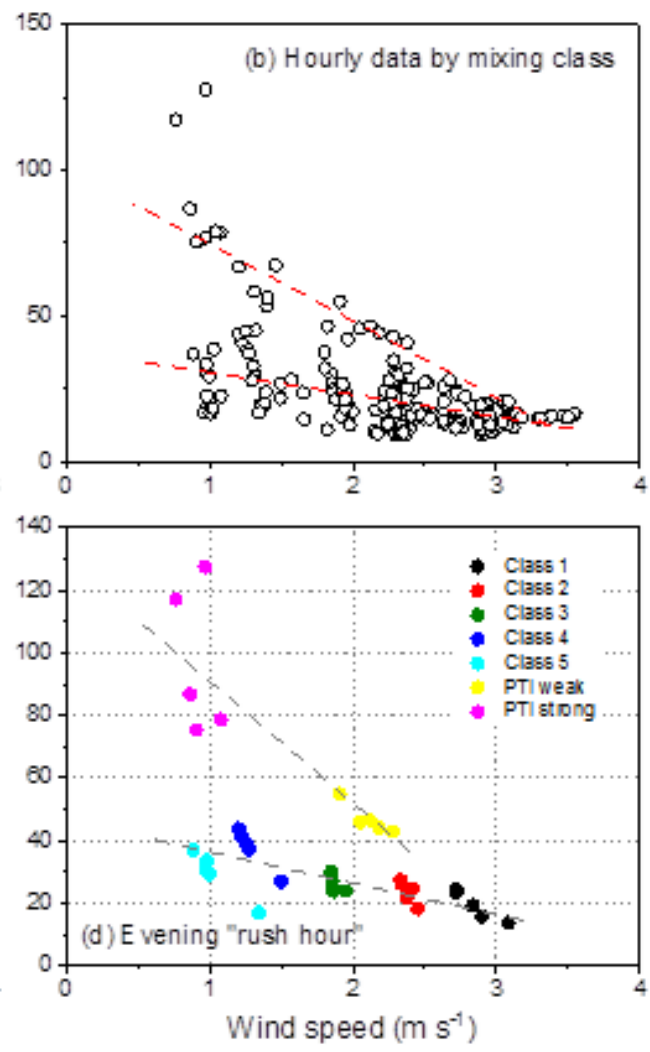

Fig. 4. Relationship between Zgierz $\mathrm{PM}_{2.5}$ and wind speed. 

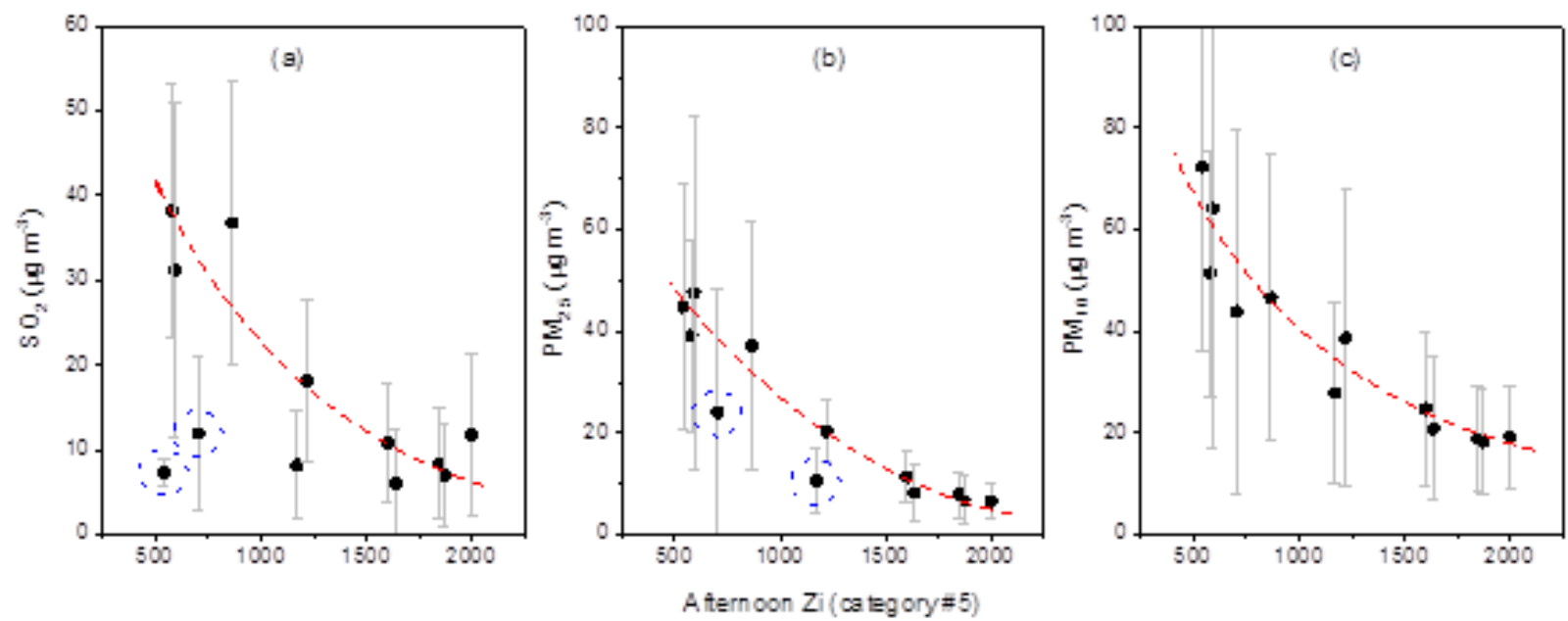

Fig. 5. Relationships between mean-monthly afternoon $\mathrm{Zi}$ and (a) $\mathrm{SO}_{2}$, (b) $\mathrm{PM}_{2.5}$ and (c) $\mathrm{PM}_{10}$ (adapted from Chambers and Podstawczyńska [14]).

dilution are less variable. Under these restricted conditions, the relationship between Zgierz $\mathrm{PM}_{2.5}$ and wind speed becomes much clearer and it is quite different for PTI and non-PTI conditions.

Historically, relationships between $\mathrm{PM}_{10}$ concentration and the atmospheric boundary layer depth (Zi) have also been difficult to formalize. As an example, Jędruszkiewicz et al. [18] concluded that "the relationship between $\mathrm{Zi}$ and $\mathrm{PM}_{10}$ exhibits complex non-linear cause-and-effect dependencies", only with their winter results giving relatively consistent relationships. To further demonstrate the benefits of radon-based 'class typing' in this regard, we selected results from a single mixing class (\#5) and investigated the relationship between mean-monthly afternoon $\mathrm{PM}_{10}, \mathrm{PM}_{2.5}$ and $\mathrm{SO}_{2}$ and afternoon mixing height estimates for the region (as retrieved from HYSPLIT v4) [19] (Fig. 5). Afternoon values were chosen since this is the time of most representative $\mathrm{Zi}$ estimates from HYSPLIT. Class \#5 afternoons are typically characterized by clear skies and regional scale subsidence. The most consistent relationship was observed between $\mathrm{Zi}$ and $\mathrm{PM}_{10}$ (Fig. 5c). The progressively increasing scatter for the $\mathrm{PM}_{2.5}$ and $\mathrm{SO}_{2}$ (the largest outliers circled in blue) may be attributable to secondary photochemical reactions expected under class \#5 conditions.

\section{Conclusions}

Four years of observation of radon, meteorology and pollution was used to demonstrate the efficacy of combined diurnal and synoptic timescale radon-based stability classification schemes in relating atmospheric mixing state to urban air quality in Central Poland. Nocturnal radon measurements were used to identify and remove periods of non-stationary synoptic behaviour and classify the remaining data into five mixing states, including PTI conditions and non-PTI conditions with nocturnal conditions ranging from well mixed to stable.

WHO guideline values for daily $\mathrm{PM}_{2.5} / \mathrm{PM}_{10}$ were exceeded only in non-summer months under strong
PTI conditions (3-15\% of non-summer months) or often under non-PTI stable nocturnal conditions (14-20\% of non-summer months). Radon-based classification of the mixing state may therefore prove to be a simple, economical alternative to detailed meteorological measurements to better quantify potential exposure to harmful pollutants in public health studies.

Statistically robust characterization of diurnal cycles of meteorological parameters as well as traffic and heating-related gaseous pollutants were derived for each of the radon-derived atmospheric mixing state for each season. This information will provide a useful benchmark for future studies assessing the need for, or efficacy of, pollution mitigation measures in this region. It could also be used as benchmarking data for the evaluation of regional chemical transport model performance.

Finally, it was clearly demonstrated that by analysing meteorological and air quality observations within radon-derived atmospheric mixing 'class types' (for which within-class variability is constrained) it is possible to substantially improve the clarity of relationships between meteorological and air quality parameters, including wind speed vs. $\mathrm{PM}_{2.5}$ concentration, and atmospheric mixing depth vs. $\mathrm{PM}_{10}, \mathrm{PM}_{2.5}$ or $\mathrm{SO}_{2}$ concentration.

\section{ORCID}

S. D. Chambers (1) http://orcid.org/0000-0002-2521-959X A. Podstawczyńska (1) http://orcid.org/0000-0001-6353-9976

\section{References}

1. Apte, J. S., Brauer, M., Cohen, A. J., Ezzati, M., \& Pope III, C. A. (2018). Ambient $\mathrm{PM}_{2.5}$ reduces global and regional life expectancy. Environ. Sci. Technol. Lett., 5(9), 546-551.

2. Lelieveld, J., Klingmuller, K., Pozzer, A., Pöschl, U., Fnais, M., Daiber, A., \& Münzel, T. (2019). Cardiovascular disease burden from ambient air pollution 
in Europe reassessed using novel hazard ratio functions. Eur. Heart J., 40(20), 1590-1596. https://doi. org/10.1093/eurheartj/ehz135.

3. Ayers, G. P., Bigg, E. K., Turvey, D. E., \& Manton, M. J. (1982). Urban influence on condensation nuclei over a continent. Atmos. Environ., 16, 951-954.

4. Chambers, S. D., Guérette, E. -A., Monk, K., Griffiths, A. D., Zhang, Y., Duc, H., Cope, M., Emmerson, K. M., Chang, L. T., Silver, J. D., Utembe, S., Crawford, J., Williams, A. G., \& Keywood, M. (2019a). Skilltesting chemical transport models across contrasting atmospheric mixing states using Radon-222. Atmosphere, 10(1), 25. https://doi.org/10.3390/ atmos 10010025.

5. Chambers, S. D., Podstawczyńska, A., Pawlak, W., Fortuniak, K., Wiliams, A. G., \& Griffiths, A. D. (2019b). Characterising the state of the urban surface layer using radon-222. J. Geophys. Res. Atmos., 124(2), 770-788.

6. Chambers, S. D., Williams, A. G., Crawford, J., \& Griffiths, A. D. (2015). On the use of radon for quantifying the effects of atmospheric stability on urban emissions. Atmos. Chem. Phys., 15, 1175-1190.

7. Kikaj, D., Vaupotič, J., \& Chambers, S. D. (2019a). Identifying "persistent temperature inversion" events in a sub-Alpine Basin using Radon-222. Atmos. Meas. Tech., 12, 4455-4477. https://doi.org/10.5194/amt12-4455-2019.

8. Kikaj, D., Chambers, S. D., \& Vaupotič, J. (2019b). Radon-based atmospheric stability classification in contrasting sub-Alpine and sub-Mediterranean environments. J. Environ. Radioact., 203, 125-134. DOI: 10.1016/j.jenvrad.2019.03.010.

9. Moses, H., Stehney, A. F., \& Lucas, H. J. (1960). The effect of meteorological variables upon the vertical and temporal distributions of atmospheric radon. $J$. Geophys. Res., 65, 1223-1238.

10. Perrino, C., Pietrodangelo, A., \& Febo, A. (2001). An atmospheric stability index based on radon progeny measurements for the evaluation of primary urban pollution. Atmos. Environ., 35, 5235-5244.

11. Williams, A. G., Chambers, S. D., \& Griffiths, A. D. (2013). Bulk mixing and decoupling of the nocturnal stable boundary layer characterized using a ubiquitous natural tracer. Bound. Layer Meteorol., 20(149), 381-402.
12. Williams, A. G., Chambers, S. D., Conen, F., Reimann, S., Hill, M., Griffiths, A. D., \& Crawford, J. (2016). Radon as a tracer of atmospheric influences on traffic-related air pollution in a small inland city. Tellus $B, 68,30967$. http://dx.doi.org/10.3402/tellusb. v68.30967.

13. Podstawczyńska, A., \& Chambers, S. D. (2019). Improved method for characterising temporal variability in urban air quality Part I: Traffic emissions in Central Poland. Atmos. Environ., 219, 117038. https://doi. org/10.1016/j.atmosenv.2019.117038.

14. Chambers, S. D., \& Podstawczyńska, A. (2019). Improved method for characterising temporal variability in urban air quality Part II: particulate matter and precursors in central Poland. Atmos. Environ., 219, 117040. https://doi.org/10.1016/j. atmosenv.2019.117040.

15. Grossi, C., Arnold, D., Adame, A. J., Lopez-Colo, L., Bolivar, J. P., de la Morena, B. A., \& Vargas, A. (2012). Atmospheric ${ }^{222} \mathrm{Rn}$ concentration and source term at El Arenosillo 100m meteorological tower in southwest, Spain. Radiat. Meas., 47, 149-162.

16. Schmithüsen, D., Chambers, S. D., Fischer, B., Gilge, S., Hatakka, J., Kazan, V., Neubert, R., Paatero, J., Ramonet, M., Schlosser, C., Schmid, S., Vermeulen, A., \& Levinet, I. (2017). A European wide ${ }^{222}$ Radon and ${ }^{222}$ Radon progeny comparison study. Atmos. Meas. Tech., 10, 1299-1312.

17. Williams, A. G., \& Chambers, S. D. (2016). A history of radon measurements at Cape Grim. In N. Derek, P. B. Krummel \& S. J. Cleland (Eds.), Baseline Atmospheric Program (Australia) History and Recollections (40th Anniversary Special ed.) (pp. 131-146). Australia: Burreau of Metrology/CSIRO Oceans and Atmosphere.

18. Jędruszkiewicz, J., Czernecki, B., \& Marosz, M. (2017). The variability of $\mathrm{PM}_{10}$ and $\mathrm{PM}_{2.5}$ concentrations in selected Polish agglomerations: the role of meteorological conditions, 2006-2016. Int. J. Environ. Health, 27, 441-462.

19. Draxler, R. R., \& Rolph, G. D. (2003). Hybrid Single-Particle Lagrangian Integrated Trajectory (HYSPLIT) Model. Retrieved July 31, 2019, from http:// www.arl.noaa.gov/ready/hysplit4.html. 